\title{
Learning Objective and Assessment Linkage: Its Contribution to Meaningful Student Learning
}

\author{
Abatihun Alehegn Sewagegn \\ Department of Educational Psychology, Faculty of Education, University of Johannesburg, Johannesburg, South Africa
}

Received May 31, 2020; Revised September 3, 2020; Accepted September 11, 2020

\section{Cite This Paper in the following Citation Styles}

(a): [1] Abatihun Alehegn Sewagegn, "Learning Objective and Assessment Linkage: Its Contribution to Meaningful Students Learning," Universal Journal of Educational Research, Vol. 8, No. 11, pp. 5044-5052, 2020. DOI: 10.13189/ujer.2020.081104.

(b): Abatihun Alehegn Sewagegn (2020). Learning Objective and Assessment Linkage: Its Contribution to Meaningful Students Learning. Universal Journal of Educational Research, 8(11), 5044-5052. DOI: 10.13189/ujer.2020.081104.

Copyright $\mathrm{C} 2020$ by authors, all rights reserved. Authors agree that this article remains permanently open access under the terms of the Creative Commons Attribution License 4.0 International License

\begin{abstract}
Any instructional activity begins with introducing the lesson topic and learning objectives to the students. Learning objectives are the expected behavioral outcomes of the students at the end of a certain instructional process, and assessment is the process of gathering evidence or information about the students' learning to check whether or not the students achieved the stated learning objectives. Before beginning a certain instruction, the teacher has to communicate the learning objectives to the students for various reasons. But there are often gaps in integrating learning objectives with assessment at different education levels. To have meaningful student learning, assessment and learning objectives should be linked. Therefore, the objective of this review article is to clearly outline and discuss the link between learning objectives and assessment and its contribution to students' learning. This study is a review of different literatures in the area of teaching, learning, and assessment. The resources included in the review were identified by manual searches from online databases and library catalogues. From the review, it is concluded that writing clear and meaningful learning objectives is a necessary skill that teachers need to have in the academic environment and the proper linkage of learning objectives and assessment plays a significant role in the success of students' learning.
\end{abstract}

Keywords Assessment, Domains, Learning, Learning Objective, Linkage, Objective, Students

\section{Introduction}

Higher learning institutions play a substantial role in advancing knowledge, improving the living standards of citizens, and the development of a country as a whole. For this to happen, students' learning should be meaningful. Meaningful student learning occurs when the teaching learning process, assessment, and objectives are linked. The proper linkage of objectives, assessment, and teaching strategies produces meaningful results from students. Governments, employers, and students all over the world have been making demands upon universities to improve the quality of teaching [1]. Linking educational components (learning objectives, assessment, and teaching strategies) is one means of improving the quality of teaching. Teaching without learning objectives and assessment has no value. Therefore, the objective of this review article is to clearly outline and discuss the link between learning objectives and assessment and its contribution to students' learning.

Learning objectives and assessment are the core elements of any instructional activity. The proper linkage between learning objectives and assessment will play a vital role in students' learning. Oermann and Gaberson [2] indicate that objectives play a significant role in teaching students in diverse settings and provide guidelines for student learning and a base for evaluation. Another author's definition is that a "learning objective is a description of what the learner must be able to do upon completion of an educational activity, and a well-written learning objective outlines the knowledge, skills and/or 
attitude the learners will gain from the educational activity and does so in a measurable way" [3,pp.1]. Chatterjee and Corral [3] also note that well-stated learning objectives guide the assessment method and the teaching by defining and limiting content or activities. However, gaps are observed in linking and using learning objectives with assessment and the teaching learning process in the practical environment. Therefore, to have meaningful student learning, assessment and learning objectives should be linked.

Biggs [4] calls the linkage between objectives, assessments, and teaching a constructive alignment. The 'constructive' aspect refers to the idea that students construct meaning through relevant learning activities. Biggs [4] adds that the teaching method and the assessment tasks used are aligned to the learning activities that are assumed in the intended outcomes. According to Chatterjee and Corral [3], "learning objectives contribute to shaping expectations, preparing learners for the educational activity and standard by which their performance will be measured; the objectives also define teacher and learner responsibilities towards achieving the intended learning outcomes" [pp.1].

As it is noted in most literatures, learning objectives and assessment are inseparable. Before beginning a certain instruction, the teacher has to present or communicate the learning objectives to the students for various reasons. First, the students attend the lesson, giving attention when the teacher describes what is expected from them at the end of the instruction or lesson. Second, the objective guides the teacher in developing an assessment method [3, 5]. Nitko and Brookhart [5] add that the clearer the teacher is about what will be assessed, the more effective the assessment will be. Third, the learning objectives guide the teacher to select the appropriate teaching method for the lesson $[3,6]$.

However, most teachers lack the ability to link the objective with the assessment tool they are using, and this is the major problem that most teachers in higher institutions face. As to the author's observation, teachers begin their instruction without introducing the lesson objective. Pedagogically this is not advisable. According to Kennedy [7], lack of clarity in learning objectives and improper linkage with assessment and teaching strategies creates learning difficulties and yields negative evaluations of student performance.

\section{Materials and Methods}

This study is a review of the global literatures in the area of teaching, learning, and assessment. In addition, ideas from the author's teaching experience and observations of other teachers are incorporated in this review study. A total of 92 articles which were written between 2000 and 2020 were identified. Based on the objective of this review article, 25 articles (books, journals, thesis, and dissertations, proceedings, and teaching materials) were selected and reviewed. The resources included in the review were identified by manual searches from online databases and library catalogues from the University of Johannesburg (South Africa).This article has no specific scope, which means it is not specific to South Africa even if the author has written the article in South Africa. The ideas in this article are shared from the South African, USA, and other countries' perspective. Therefore, the perspective is universal. The data from the reviews were analysed and interpreted using descriptive-narrative analysis. The analysis and discussions of studies are presented based on the topics identified and the objective, and finally, conclusions are given.

\section{Discussion}

\subsection{The Link between Learning Objectives and Assessment}

Objectives are expected behavioral outcomes at the end of a particular instructional process and help a teacher to plan instruction, guide students' learning, and provide criteria for evaluating student outcomes [8]. Learning objectives are also called educational or specific objectives. Learning objectives are statements that describe what a student should be able to do at the end of a lesson. In educational settings, the assessment activities are based on the objectives stated. Objectives are logically and closely linked to assessment, since one critical role of assessment is to determine how well students have learned the intended learning objectives. In general, objectives give direction to education.

In different literatures, the terms 'learning objective' and 'learning outcome' are used interchangeably. For example, Harden [9] confirms that the terms 'instructional objectives' and 'learning outcomes' are often equally used. Kennedy [7] states that, "learning outcomes are statements of what a student is expected to know, understand and/or be able to demonstrate at the end of an instructional process" [pp. 20].

Learning objectives help to determine the selection of learning experiences, learning activities, and methods of evaluation $[6,10,8]$. According to Sewagegn [11], learning objectives help to select appropriate assessment methods. Sewagegn [11] adds that, assessment methods are tools used to check the extent to which the learning objectives are attained or not. Good assessment has a closer link with learning objectives and provides feedback to the students about their learning and to teachers about their instruction.

Pedagogically it is advised that stating or communicating objectives to the students before delivering the actual instruction is vital because the assessment is implemented based on the stated objectives. According to Dean, Hubbell, Pitler, and Stone [12] "when teachers communicate objectives for student learning, students can 
see more clearly the connections between what they are doing in class and what they are supposed to learn" [pp.3]. Other studies also indicate that well-stated objectives will give direction to the choice of assessment to be used. However, there are often gaps in communicating and stating the objectives to students, and teachers find they do not know what to assess. Their assessment becomes meaningless and it may be just a matter of formality. Therefore, a good link between the learning objectives and assessment is very important to clearly evaluate the competency of the students.

The link or alignment between learning objectives, assessment, and teaching strategies has a paramount contribution to the effectiveness of the teaching and learning process in particular and quality of education in general. Biggs and Tang as cited in Wijngaards-De Meij and Merx [13] state that alignment is the constructive coherence between teaching, learning, and assessment and it is crucial for the quality of teaching. Kennedy [7] for his part notes that the connection between teaching, assessment, and learning outcomes helps to make the overall learning experience more transparent and meaningful for students. According to FitzPatrick, Hawboldt, Doyle, and Genge [14], learning objectives and assessments should be aligned and work seamlessly to promote high quality education and support student learning.

Alignment is matching educational components (objectives, assessment, and teaching strategies) with one another so that they work together to improve students' learning [15]. As it is also clearly discussed in the Eberly Center [15], the alignment between the three components (objectives, assessment, and teaching strategies) ensures an internally consistent structure. When the teaching and learning activities and assessment methods are linked with the objectives, then there is alignment [6]. Hence, according to Eberly Center [15, pp.2], alignment is when the "assessments allow the teacher to check the degree to which the students are attaining the learning objectives; objectives articulate the knowledge and skills you want students to acquire by the end of the lesson or course; teaching strategies are chosen to foster student learning towards attaining the objectives".

Matching and creating coherence among all components helps teachers and students to achieve the learning outcomes. In addition, it is important to properly measure the effectiveness of the instruction to keep the students and teachers moving in the right direction which is helpful in measuring the students learning. In this way, students and teachers can achieve success. However, if a mismatch or misalignment of the components is created, then there is a risk of not teaching the learning outcomes, or perhaps teaching them improperly and evaluating students in the incorrect way. In addition, if there is misalignment between the three components, it undermines the students' motivation and learning. This could cause students to receive mixed messages and end up spending time on meaningless activities that have no academic purpose. Consider the following example to see the misalignment between a lesson objective and an activity related to the objective.

Lesson objective: At the end of this topic, learners will be able to create a plan of action.

Activity: Identify the components of an action plan.

In the above example, the objective and the activity used to check the attainment of the objectives are not matched. Therefore, the objective or the activity should be revised to ensure appropriate alignment. A detailed discussion is presented below on the statement of learning objectives.

When assessments are developed, its alignment with the learning objectives should be checked. According to Fuentealba [16], students' assessment should be linked with educational objectives. If assessments and objectives are linked, then students have the chance to meet the expectations of the course or the topic [14]. Hence, in formulating an assessment it is vital to see what is assessed and how it is assessed and how it should be linked to the learning outcome. Each learning outcome in the course or in a lesson topic should be assessed. If the stated objective is not assessed, neither the teacher nor the students will know if it has been realized.

An effective learning outcome statement informs and guides both the teacher and the students. Using a single assessment method, a number of learning outcomes can be measured. However, if a teacher always uses the same particular teaching style and assessment method, there is a risk that students will not achieve the learning outcomes of the program [17].

According to Kennedy [7], three basic areas are involved in the constructive alignment of any subject:

- Clearly formulate the learning outcomes.

- Select teaching methods which help to achieve the learning outcomes formulated.

- Assessing the student learning outcomes and checking to see how well they match with what was intended.

The table given/shown below shows the link between the action verbs used to state the learning objectives of the three domains and the possible assessment methods which will be used. 
Table 1. Link between learning objective and assessment

\begin{tabular}{|c|c|c|c|}
\hline \multicolumn{2}{|c|}{$\begin{array}{l}\text { Levels/types of learning outcomes of the } \\
\text { three domains }\end{array}$} & \multirow{2}{*}{$\begin{array}{l}\text { Learning objective/outcome example and list } \\
\text { of action verbs } \\
\text { Students will be able to: order, relate, recall, } \\
\text { state, list, identify, define, label, outline, name, } \\
\text { describe, match, reproduce, select, record, } \\
\text { repeat, etc... }\end{array}$} & Possible assessment method \\
\hline \multirow{6}{*}{$\begin{array}{l}\text { Cognitive } \\
\text { level } \\
\text { (The revised } \\
\text { levels of } \\
\text { cognitive } \\
\text { domain) }\end{array}$} & Remembering & & $\begin{array}{c}\text { Test items such as completion, short } \\
\text { answer, multiple choice, matching and } \\
\text { interpretive exercises or labeling } \\
\text { diagrams }\end{array}$ \\
\hline & Comprehension & $\begin{array}{l}\text { Students will be able to: describe, explain, } \\
\text { compare, infer, exemplify, classify, identify, } \\
\text { summarize, interpret, estimate, extend, } \\
\text { generalize, express, review, discuss, report, } \\
\text { express, differentiate, illustrate, etc... }\end{array}$ & $\begin{array}{l}\text { Group or individual assignments, } \\
\text { class discussions, oral or written exam } \\
\text { questions, concept maps }\end{array}$ \\
\hline & Application & $\begin{array}{l}\text { Students will be able to: change, apply, } \\
\text { calculate, compute, operate, demonstrate, } \\
\text { discover, produce, manipulate, modify, } \\
\text { prepare, relate, practice, solve, use, show, } \\
\text { employ, intervene, illustrate, etc... }\end{array}$ & $\begin{array}{l}\text { Activities such as problem sets, } \\
\text { performances, labs, prototyping, or } \\
\text { simulations that require students to: } \\
\text { use procedures to solve familiar or } \\
\text { unfamiliar tasks, determine which } \\
\text { procedure(s) are most appropriate for } \\
\text { a given task }\end{array}$ \\
\hline & Analysis & $\begin{array}{l}\text { Students will be able to: classify, analyze, } \\
\text { diagram, contrast, categorize, distinguish, } \\
\text { differentiate, calculate, survey, inspect, } \\
\text { illustrate, criticize, debate, infer, relate, select, } \\
\text { compare, etc... }\end{array}$ & $\begin{array}{l}\text { Activities such as case studies, } \\
\text { critiques, projects, debates, or concept } \\
\text { maps that require students to: separate } \\
\text { or select relevant and irrelevant parts, } \\
\text { determine how elements function } \\
\text { together, determine bias, values, or } \\
\text { underlying intent in presented } \\
\text { material }\end{array}$ \\
\hline & Evaluation & $\begin{array}{l}\text { Students will be able to: judge, recommend, } \\
\text { compare, conclude, appraise, argue, contrast, } \\
\text { criticize, discriminate, evaluate, validate, } \\
\text { revise, justify, critique, relate, value, } \\
\text { summarize, etc... }\end{array}$ & $\begin{array}{l}\text { Activities such as problem sets, } \\
\text { journals, critiques, product reviews, or } \\
\text { studies that require students to: test, } \\
\text { monitor, judge, or critique readings, } \\
\text { performances, or products against } \\
\text { established criteria or standards }\end{array}$ \\
\hline & Creating & $\begin{array}{l}\text { Students will be able to: construct, compose, } \\
\text { propose, design, build, plan, assemble, repair, } \\
\text { formulate, set up, produce, invent, develop, } \\
\text { summarize }\end{array}$ & $\begin{array}{l}\text { Activities such as essays, research } \\
\text { projects, performances, business } \\
\text { plans, website designs that require } \\
\text { students to: build, make, design or } \\
\text { generate something new }\end{array}$ \\
\hline \multirow[b]{5}{*}{ Affective } & Receiving & \multirow{5}{*}{$\begin{array}{l}\text { Students will be able to: listen, attend, share, } \\
\text { look, notice, be aware, control, hear, act, } \\
\text { follow, play, practice, participate, discuss, } \\
\text { applaud, comply, obey, help, express, act, } \\
\text { argue, debate, organize, convince, prefer, } \\
\text { select, decide, formulate, balance, abstract, } \\
\text { systematize, compare, define, display, manage, } \\
\text { exhibit, require, internalize, avoid, resolve, } \\
\text { resist, accept, ask, appreciate, revise, adhere, } \\
\text { combine, share, challenge, attempt, answer, } \\
\text { assist, conform, complete, co-operate, dispute, } \\
\text { defend, praise, order, justify, integrate, } \\
\text { embrace, hold, initiate, report, relate, judge, } \\
\text { join, resolve, organise, synthesise }\end{array}$} & \multirow[b]{5}{*}{ Presentation, discussion, ... } \\
\hline & Responding & & \\
\hline & Valuing & & \\
\hline & Organisation & & \\
\hline & Characterization & & \\
\hline \multirow{5}{*}{ Psychomotor } & Imitation & \multirow{5}{*}{$\begin{array}{l}\text { Students will be able to: repeat, hold, follow, } \\
\text { place, grasp, balance, accurately, with control, } \\
\text { proficiently, speed, independently, without } \\
\text { error, with balance, harmony, confidence, } \\
\text { coordination, proportion, integration, timing, } \\
\text { stability, naturally, effortlessly, professionally, } \\
\text { routinely, with ease, automatically, with } \\
\text { perfection, spontaneously }\end{array}$} & \multirow{5}{*}{$\begin{array}{l}\text { Laboratory work, drawing, site/field } \\
\text { work, etc... }\end{array}$} \\
\hline & Manipulation & & \\
\hline & Precision & & \\
\hline & Articulation & & \\
\hline & Naturalization & & \\
\hline
\end{tabular}




\subsection{Selecting and Stating Learning Objectives}

Learning objectives play a pivotal role in the process of education and evaluation. According to Reck [18], learning objectives help to provide clear direction for both teachers and students on what to do. Well-stated objectives are the basis for selecting appropriate teaching methods, learning activities, and assessment methods. As Pintrich and Schunk cited in Dean et al. [12] state, setting objectives is the process of establishing a direction to guide learning. Dean et al. [12] also add that teachers should set objectives to ensure that a student's journey with learning is purposeful. However, learning objectives are not always clearly stated and communicated to the students. When teachers identify and communicate clear learning objectives, they send the message that there is a focus on learning activities to come [12]. Without a clear set of objectives, it is difficult to select the appropriate teaching method and determine whether students have achieved the expected outcomes of the course.

Teachers need to formulate objectives that guide their educational efforts, and help them focus on students' behavior. Therefore, there are two considerations in the selection of objectives. These are relevance and feasibility. Relevance refers to whether the objective is based on the needs of the learner and society, and feasibility (realism of objectives) refers to whether the objectives are achievable or not. Setting or formulating unrealistic goals or objectives discourages both students and teachers. According to Ubi [10], well-written objectives should be learner-centred, describe a learning outcome, and describe an observable product.

\subsubsection{Stating Objectives}

Well-stated learning objectives give direction to both students and teachers in the selection of teaching methods, activities, materials and evaluation methods [8]. Edinyang [8] adds that learning objectives can give students accurate statements of what is expected of them and provide guidelines for assessing their progress. As to Chatterjee and Corral's [3] discussion of their study, a well-written learning objective outlines the knowledge, skills, and/or attitude the learners will gain from the educational activity and does so in a measurable way. In developing statements of learning objectives, two major factors must be considered: content and form. Objectives should be evaluated not only for subject matter (content) but also how the subject matter is treated or expressed (form). These two dimensions are significantly related and can influence the usefulness of objectives and the quality of the resulting test items [19]. These authors also describe the desirable characteristics of objectives in terms of both content and form as follows.

\section{A. Stating objectives in terms of contents}

1. The learning objectives should be appropriate for the level of difficulty and prior learning experiences.

It means that learning objectives should be developmentally appropriate. Teachers should consider the developmental stages of the students they are teaching. The objectives that the teachers state and use should not be difficult for the students to achieve and should take their prior learning experiences into consideration. The content of the objectives should be easily understood by the students.

2. Objectives should be "real" in a sense that they describe behaviors that the teacher actually intends to act on in the classroom situation.

Frequently, teachers will state objectives in such a way that they intend to bring about changes in the 'attitudes' and 'appreciations' of their students, but plan no specific learning experiences to achieve these kinds of objectives. These are, of course, useful or desirable objectives, but if you adopt an objective, you must evaluate students' progress towards it. However, it is difficult to measure or evaluate these types of objectives. Conversely, if an objective is not part of the actual instructional program, you should not evaluate it.

Example: Poor: Students will learn to love science.

Better: After a visit to a local hospital, pharmacy students will better appreciate the importance of scientific experimentation.

3. The objective should describe the overt behavior expected and the content.

Learning objectives emphasize observed activity or behavior of the students. In short, learning objectives should be observable. This means it should describe an observable action, lead to clear expectations, and should be easy to determine whether the objective is achieved or not. According to Ubi [10, pp. 152], "the important thing in writing observable objectives is to use verbs that are observable and lead to a well-defined product of the action implied by that verb".

Verbs such as learn, know, understand, enjoy, realize, and appreciate are not observable. Verbs such as list, state, label, match, identify, select, predict, and define are explicit and describe observable actions [10].

Example: Poor: Students will know the world capitals. Better: Students will be able to recall the capitals of the countries in eastern Africa.

4. The content of objectives should be responsive to the needs of both individual and society.

The objectives that the teachers' state should consider the needs of the students and other beneficiaries. It means that the objective should have relevance to the learner and the society. 


\section{B. Stating objectives in terms of form}

1. Objectives should be stated in terms of the students' behavior, not in terms of the teacher's activities; this means that the learning objectives should be student oriented. A student-oriented objective describes what the student will be expected to be able to do and not the teacher's activity [10].

Example: Poor: The teacher will describe the major events in the Ethio-Italian war.

Better: The student will recall the military event that directly led to the outbreak of war between Ethiopia and Italy.

The first objective is not stated in terms of students' behavior. It is an activity of the teacher. What are the students expected to do when the teacher describes the major events in the Ethio-Italian war? We do not know what students are expected to do. Hence, the second objective is appropriate, because it is stated in terms of students' behavior.

2. Objectives should be stated in behavioral or performance terms. The terms used should have the same meaning for students and teachers. Objectives must be stated in specific terms if teachers are to evaluate them adequately.

Example: Poor: The student will see the importance of education.

Better: The student will be able to identify three factors that highlight the importance of education.

3. Objectives should be stated singly.

When we state objectives, we should include only one behavior. Kennedy [7] in his guideline indicates the use of only one verb per learning outcome. Compound objectives, objectives that include two or more behaviors, are likely to lead to inconsistent measurement. At the beginning of a course, a teacher may have a particular objective, such as, "The student should be able to recall, comprehend, and apply the process of item analysis". But any of these three behaviors (recall, comprehend, and apply) may measure the achievement of this objective. In addition, those selected may or may not be measured in proportion to the emphasis given to them in class. If the resulting test is not responsive to the instructional objectives, it is invalid for determining whether these objectives have been accomplished. Another shortcoming of compound objectives is that the easier proportions of the objectives may be measured because it is easier to write recall (knowledge) items than application items. Again, the relevance of the test is distorted.

\subsection{Components of Learning Objectives}

A learning objective contains three major components.

\section{Behavior}

Behaviour is an observable action that is supposed to be accomplished by the learners at the end of the instructional process. This component is the heart of the objective and it should be measurable, specific, and observable. Verbs like define, list, state, select, label, match, etc ... are appropriate to clearly describe the behaviour. Generic verbs such as understand, know, and learn are not measurable and cannot easily show the behavior to be measured. But an assessment tool can measure whether a student can define, name, describe, select, label, describe, and differentiate.

Example: Students will summarize a book.

\section{Condition}

It describes the circumstances under which the student will learn. A learning objective should describe conditions under which the students will perform the behavior.

Example: At the end of the course, students will summarize and present the issue that they have learnt in the class.

\section{Criteria}

It describes the degree of measurement or the standard that the student must achieve to demonstrate an acceptable performance (time, accuracy, proportion, quality, etc). For example, phrases like 'within 3 minutes', 'without error', 'out of $100 \%$ ' can be used in the stated objective to indicate the criteria.

Example: At the end of a course, students will solve a mathematical problem and score their answer using the answer key out of $50 \%$.

\subsection{Categories of Learning Objectives}

Benjamin Bloom (an American educational psychologist) and his associates developed systems in 1956 for classifying learning outcomes and identifying behavior that can be expected of learners. They referred to their respective classification schemes as taxonomies of behavioral objectives since they are intended as targets or goals of instruction. Accordingly, they categorized learning objectives into three domains [20]:

i. The cognitive domain which represents intellectual abilities and skills.

ii. The affective domain which represents attitudes, feelings, interests, beliefs, and values.

iii. The psychomotor domain which represents bodily movements and physical performance.

According to Edinyang [21], good learning objectives give due recognition to the three domains of learning because students are expected to be given a wholesome development. 


\subsubsection{The cognitive domain}

This domain involves knowledge and the development of intellectual or mental skills [21] and it is the most commonly assessed school behavior. Ubi [10] indicates that the cognitive domain includes a range of intellectual activities such as memorizing, interpreting, applying, problem solving, analyzing, drawing conclusions, and thinking critically. According to Kennedy [7], Bloom categorized this domain into six levels, from the simple recall of facts at the lowest level to evaluation at the highest level (remembering, understanding, applying, analysing, synthesising, and evaluating).

A newer version of Bloom's taxonomy places creating as the most complex learning activity that can be performed to show one's learning mastery. Table 2 shows the levels of cognitive domain from the least complex (remembering) to the most complex (creating).

\subsubsection{Affective domain}

This is the second category for grouping instructional objectives. According to Edinyang [21], the affective domain deals with developing learners' feelings, emotions, appreciations, interests, preferences, values, and modes of adjustment especially in modifying their attitudes towards things and persons. This domain was developed by David Krathwohl and divided into five levels [21]. Teachers assess affective behavior informally in schools and describe their students' affective characteristics based on their informal observations and interactions with the students. Table 3 below shows the levels of the affective domain.

The action verbs which will be used to state objectives at each level of the affective domain are listed in Table 1.

Table 2. Levels of cognitive domain

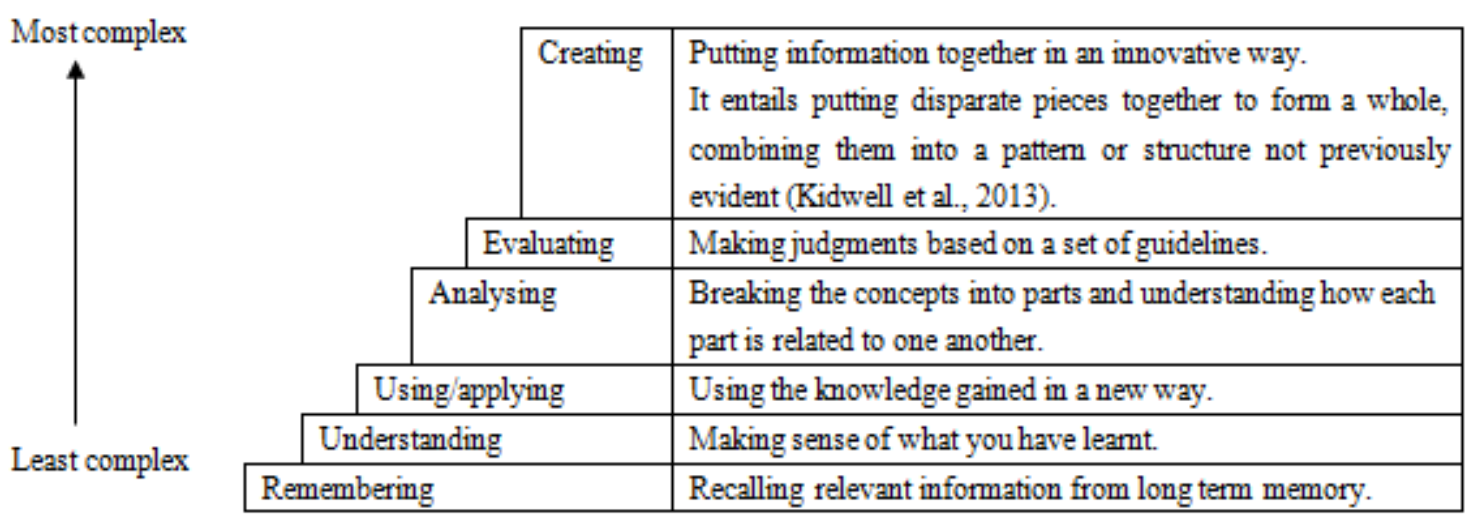

Source: Adapted from https://www.flickr.com/photos/53801255@N07/7095644699/in/photostream/

Table 3. Levels of affective domain

\begin{tabular}{|c|c|c|}
\hline \multirow[t]{4}{*}{ Most complex } & Characterization & $\begin{array}{l}\text { Objectives at the characterization level require that all the } \\
\text { behavior displayed by the student be consistent with his or her } \\
\text { values. }\end{array}$ \\
\hline & Organization & $\begin{array}{l}\text { The student is committed to a set of values and displays or } \\
\text { communicates his or her beliefs or values. }\end{array}$ \\
\hline & Valuing & $\begin{array}{l}\text { The student displays a behavior consistent with a single belief or } \\
\text { attitude in situations where he/she is not forced to comply or } \\
\text { obey. }\end{array}$ \\
\hline & Responding & $\begin{array}{l}\text { The students' response at this level indicates more than passive } \\
\text { listening and attending; they require active participation. }\end{array}$ \\
\hline Least complex & Receiving (Attending) & $\begin{array}{l}\text { The student is aware of, or passively attending to, certain } \\
\text { phenomena and stimuli (that is, listening, observing). }\end{array}$ \\
\hline
\end{tabular}


Table 4. Levels of psychomotor domain

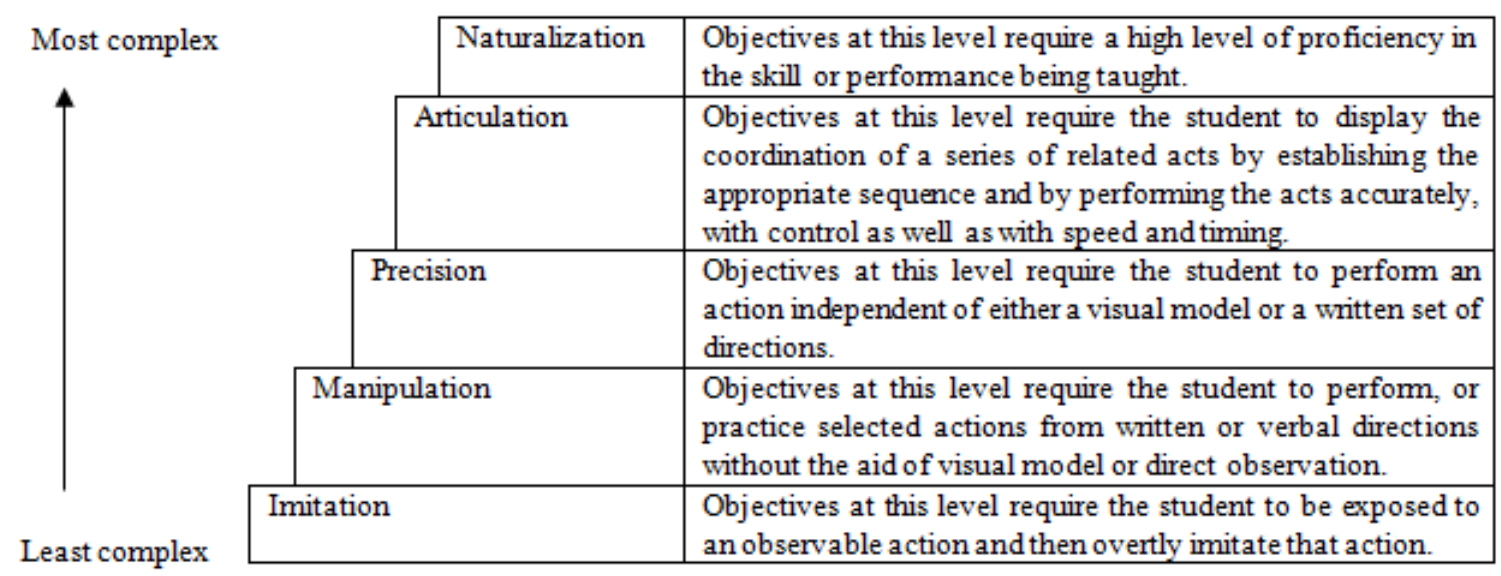

\subsubsection{Psychomotor domain}

It is the third category of grouping instructional objectives. According to Edinyang [21], the psychomotor domain involves physical manipulation, movement, coordination, and use of motor skills. This level deals with the skill of the students. For example, writing, drawing, running, jumping, speaking, typing, riding a bicycle, and driving a car, among others. It encompasses the skills that require the use of eye-hand coordination of skeletal muscles. Psychomotor behaviors are easier to measure, observe, and describe than cognitive or affective behaviors. It has five hierarchically arranged levels. The following table (Table 4) shows the levels from least complex (imitation) to most complex (naturalization).

The action verbs which will be used to state objectives at each level of the psychomotor domain are listed in Table 1.

\subsection{Benefits of Learning Objectives}

Learning objectives have a number of benefits in the instructional process and are useful both to the student and the teacher. It helps to set a shared expectation between the teachers and students. An effective learning objective statement informs and guides both the teachers and the students (Guilbert, 1984 as cited in Khan et al. [20]) for meaningful teaching and learning to take place. Mahajan and Sarjit Singh [21] list the benefits of learning objectives which are presented and summarized as follows. For the teacher, learning objectives have the following advantages:

- It informs the teaching contents.

- It helps in the selection of appropriate teaching methods and materials or aids.

- It informs the sorts of learning activities/tasks that the teacher sets for the students.

- It helps in the selection of appropriate assessment and evaluation methods.

- It helps the teacher to stick to the allotted time frame.

- It forms the foundation and is useful for the overall course evaluation and accreditation.
- It gives an opportunity for the teachers to evaluate the objective itself for future improvement based on the students' feedback.

For the students, learning objectives have the following advantages:

- It gives a clear idea to the students of what they need to learn or achieve at the end of the class.

- It helps the students to attend the lesson with a positive mindset and assists them to prepare for the assessment.

- It helps to clearly communicate to the students what is expected of them and this makes studying more efficient.

- Properly structured learning objectives can establish relevance of what is taught and learnt which acts as motivation for their learning.

\section{Conclusions}

Learning objectives and assessment are the core elements of any instructional activity. Writing clear and meaningful learning objectives is a necessary skill that teachers need to have in the academic environment. Any instructional activity begins with introducing the lesson topic and learning objectives to the students. To have meaningful student learning, assessment and learning objectives should be linked. The proper linkage of learning objectives and assessment will play a vital role in the success of student learning.

\section{REFERENCES}

[1] D. Kember, C. McNaught. Enhancing university teaching: Lessons from research into award-winning teachers, Routledge, New York, 2007.

[2] M. H. Oermann, K. B. Gaberson. Evaluation and testing in nursing education (4th ed.), Springer Publishing Company, 
LLC, New York, 2014.

[3] D. Chatterjee, J. Corral. How to write well-defined learning objectives, Journal of Education in Perioperative Medicine, Vol. 19, No.4, 1- 4, 2017.

[4] J. Biggs. Aligning teaching and assessing to course objectives. Teaching and Learning in Higher Education: New Trends and Innovations. University of Aveiro, 13-17 April, 2003.

[5] A. J. Nitko, S. M. Brookhart. Educational assessment of students $\left(6^{\text {th }}\right.$ ed.), Upper Saddle River, NJ, Pearson Education, 2011.

[6] The Center for Faculty Development. Assessment and instructional alignment: An online tutorial for faculty. University of Colorado, Denver. Retrieved from http://www.ucdenver.edu/faculty_staff/faculty/center-for-fa culty-development/Documents/tutorials/Assessment/index. htm, 2007.

[7] D. Kennedy. Writing and using learning outcomes: A practical guide, University College Cork, Cork, 2007.

[8] S.D. Edinyang. The necessity of instructional objectives in the teaching and learning of Social Studies, Education for Today, Vol. 12, No. 2, 46-52, 2016.

[9] R. M. Harden. Learning outcomes and instructional objectives: Is there a difference? Medical Teacher, Vol. 24, No. 2, 151-155, doi: 10.1080/0142159022020687, 2002.

[10] I. E. Ubi. The power and purpose of instructional objectives in Social Studies Education, Journal of Education and Practice, Vol. 5, No. 20, 150 - 153, 2014.

[11] A. A. Sewagegn. Student empowerment through instructors' assessment practices at a University in Ethiopia (Unpublished doctoral dissertation). University of South Africa, South Africa, 2016.

[12] C. B. Dean, E. R. Hubbell, H. Pitler, B. J. Stone. Classroom instruction that works: Research-based strategies for increasing student achievement $\left(2^{\text {nd }}\right.$ ed. $)$, Association for Supervision \& Curriculum Development, New York, 2012.

[13] L. Wijngaards-de Meij, S. Merx. Improving curriculum alignment and achieving learning goals by making the curriculum visible, International Journal for Academic Development, Vol. 23, No. 3, 219-231, doi: 10.1080/1360144X, 2018.

[14] B. FitzPatrick, J. Hawboldt, D. Doyle, T. Genge. Alignment of learning objectives and assessments in therapeutics courses to foster higher-order thinking, American Journal of Pharmaceutical Education, Vol. 79, No. 1, 1-9, 2015.

[15] Eberly Center. Design and Teach a Course: Articulate Your Learning Objectives. Teaching Excellence \& Educational Innovation. Retrieved 12 March, 2020, from https://www.cmu.edu/teaching/designteach/design/learning objectives.html, 2019.

[16] C. Fuentealba. The role of assessment in the student learning process, Journal of Veterinary Medical Education, Vol. 38, No.2, 157-62, doi: 10.3138/jvme.38.2.157, 2011.

[17] G. Nicholls. Developing teaching and learning in higher education. Routledge Falmer, New York, 2002.

[18] R. M. Reck. Common learning objectives for undergraduate control systems laboratories, IEEE Transactions on Education, Vol. 60, No.4, 257-264, 2017.

[19] T. Khan, S. Hande, S. Bedi, T. Singh, V. Kumar. Learning objectives, International Journal of User-Driven Healthcare, Vol. 2, No. 3, 45-63, 2012.

[20] A. A. Sewagegn, A. A. Dessie, T. Demelash. Assessment and evaluation of learning. Learning Module for summer students, Debre Markos University, Ethiopia, 2013.

[21] M. Mahajan, M. K. Sarjit Singh. Importance and benefits of learning outcomes, IOSR Journal of Humanities and Social Science (IOSR-JHSS),Vol. 22, No. 3, 65-67, 2017. 